\title{
Análise do potencial agroturístico de um distrito municipal de Itacoatiara (AM)
}

\section{Analisys of an agrotouristic potential a municipal district from Itacoatiara (AM, Brazil)}

\author{
Marcelo Veras Pacheco
}

RESUMO: Enquanto alguns autores o mostram como um fenômeno econômico não tão recente, outros apontam o turismo rural como um autêntico modelo brasileiro de atividade turística. E quando o delimitamos ao contexto amazônico, a intimidade com o meio natural é ainda mais visível. O presente trabalho visa uma análise do potencial do distrito de Novo Remanso para este segmento. Situado a oeste da cidade de Itacoatiara, a localidade tem ganhado visibilidade com a produção e comercialização do seu principal produto, o abacaxi, que abastece não só a capital, mas supre a demanda de todo o estado, e ainda é tema da festa anual que é promovida todos os anos em seu núcleo urbano, além de outros eventos culturais não menos atrativos. Como metodologia aplicada destaca-se as pesquisas bibliográficas, visitas ao distrito, registros fotográficos, etc.

PALAVRAS-CHAVE: Análise; Turismo Rural; Novo Remanso.

\section{ABSTRACT}

while some authors the show as an economic phenomenon as recent, others point the rural tourism as an authentic Brazilian model of tourist activity. And when the context Amazon able to pinpoint, intimacy with the natural environment is even more visible. The present work aims at an analysis of the potential of New Pools for this segment. Situated to the West of the town of Itacoatiara, the locale has gained visibility with the production and marketing of its flagship product, the pineapple, which supplies not only the capital, but supplies the demand across the State, and yet it's annual party theme is promoted every year in its urban core, as well as other cultural events not less attractive. How methodology applied stands out the bibliographical research, visits to the district, photographic records, etc.

KEYWORDS: Analysis; Rural tourism; Novo Remanso. 


\section{Introdução}

Uma pesquisa (2012) e parceria entre a Superintendência da Zona Franca de Manaus (SUFRAMA), a Empresa Estadual de Turismo do Amazonas (AMAZONASTUR) e o Instituto de Desenvolvimento Agropecuário e Florestal Sustentável do Amazonas (IDAM), realizada em 2008, apontou Itacoatiara como um dos sete municípios do Amazonas com maior potencial na área de turismo rural. A cidade que abriga muitos atrativos turísticos em sua sede, também expõe outros potenciais dentro de sua extensão municipal. $\mathrm{Na} z o n a$ rural da "Velha Serpa" encontram-se distritos municipais onde, entre eles, está Novo Remanso, que se destaca como o mais desenvolvido e populoso destes e tem se lançado, junto a outras 27 localidades espalhadas pelo Estado, como candidato a novo município (2011), colocando a crescente produção e comercialização do abacaxi como seu principal argumento para a separação do município-mãe. Caso fosse aprovada essa divisão, cerca de $40 \%$ da área de Itacoatiara passaria ao novo município, que ainda abarcaria, no mínimo, os distritos de Lindoia e Engenho. Além da realidade agropecuária próspera, há indícios de um possível sincretismo entre os setores primário e terciário que, no caso do último, se materializa na oferta de serviços turísticos, como uma pequena rede de pousadas, restaurantes e outras atividades. A interiorização do setor é relevante para o aproveitamento econômico e sustentável de áreas já impactadas, auxiliando na geração de empregos e divisas, na qualificação de pessoal local e, portanto, na consolidação da atividade turística em áreas rurais. Entretanto, a infraestrutura precária da sua sede, problemas ambientais e outros fatores podem ser um entrave não só ao desenvolvimento e exploração consciente do turismo rural, mas também a essa remota proposta de emancipação.

\section{Novo Remanso: análise de um potencial}

O turismo cultural em Itacoatiara, a 264 km de Manaus, há anos tem contribuído para trazer investimentos à região. Além do potencial agroturístico já identificado, a atual gestão municipal declarou recentemente à imprensa local projetos para desenvolver a "Velha Serpa" em mais dois segmentos: além da ambição de tombar a cidade como patrimônio histórico do Amazonas, algo equivalente a Ouro Preto, em Minas Gerais, há grande potencial também para o turismo arqueológico, com a possível abertura de sítios ali encontrados para visitas.

No oeste do município se encontram alguns distritos que se destacam na produção de gêneros agropecuários, como o abacaxi, gado de corte, leite e derivados, confirmando a promessa de desenvolvimento voltada para o agroturismo. No meio deles desponta o de Novo Remanso, distante $140 \mathrm{~km}$ de Itacoatiara, e pouco mais de $200 \mathrm{~km}$ da capital pela AM-010, e hoje passagem obrigatória via fluvial para alcançar a região do Baixo Amazonas e a foz do rio Madeira (Figuras 1 e 2). 


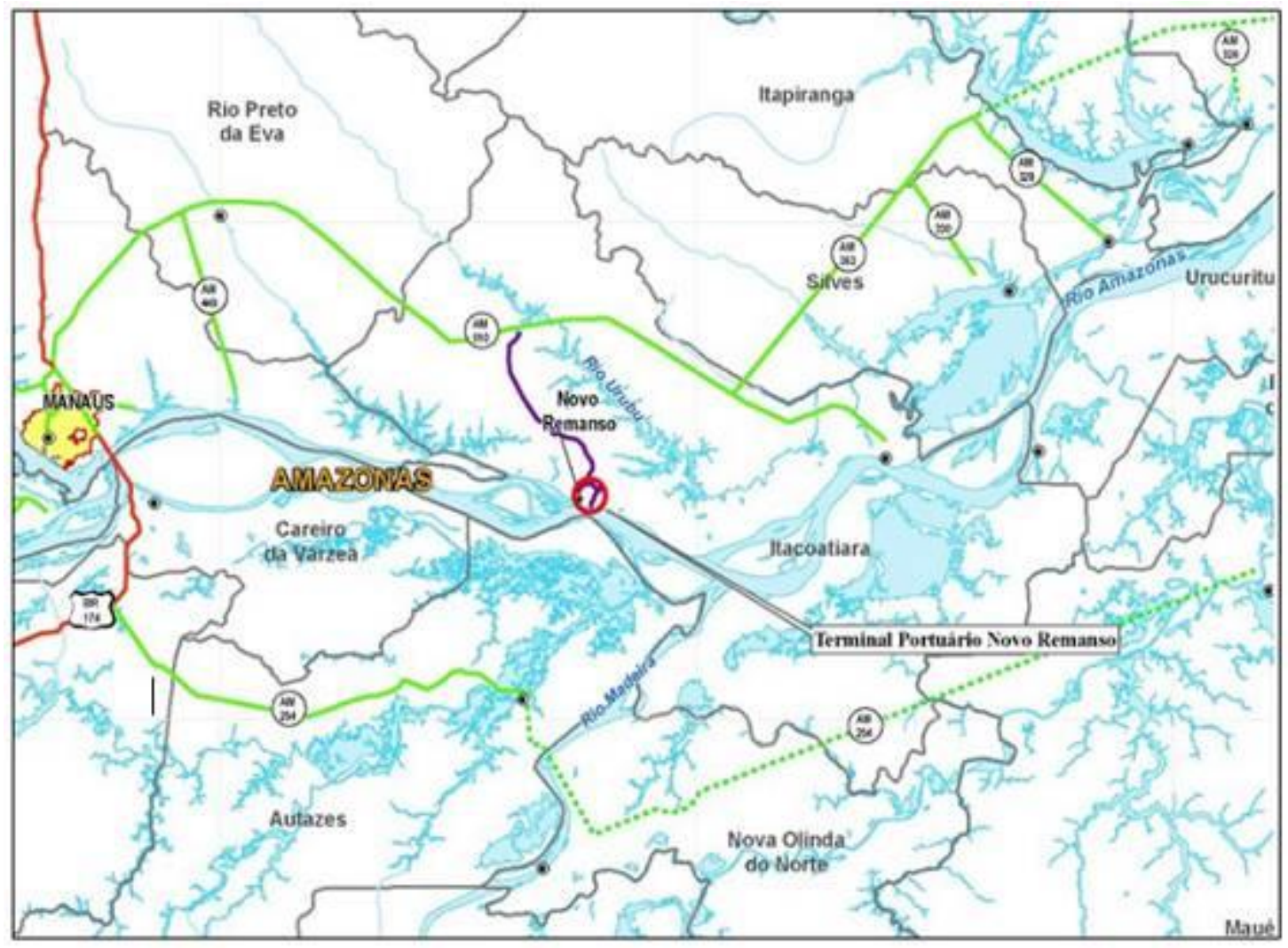

Figura 1: Localização de Novo Remanso em relação aos demais municípios.

Fonte: RIMA do Terminal Portuário de Novo Remanso.

Figure 1: Location Novo Remanso compared to other municipalities.

Source: RIMA from New Port Terminal Remanso.

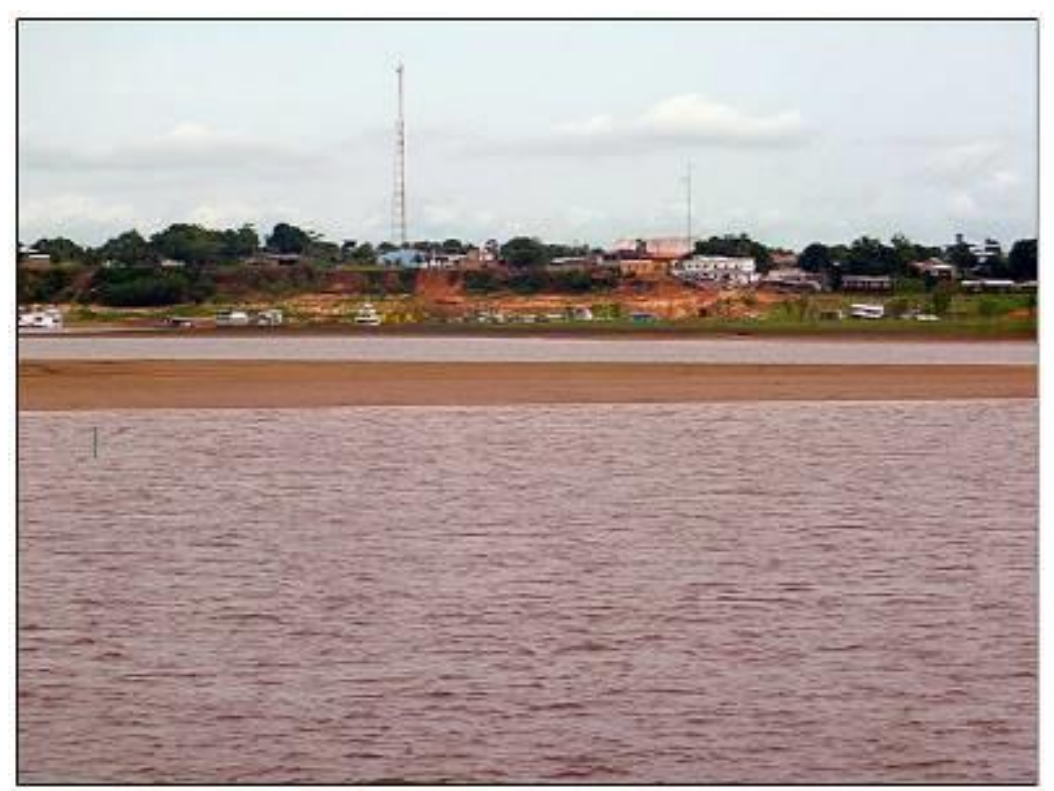

Figura 2: Sede do distrito de Novo Remanso.

Fonte: PACHECO, M. V.

Figure 2: Headquarter District from Novo Remanso.

Source: PACHECO, M.V. 
A posição estratégica - além da proximidade com Manaus -, ajudou a consolidar o seu desenvolvimento nos últimos anos, e sua importância pode aumentar ainda mais com a construção do terminal portuário que, segundo o RIMA (2015, p. 3) irá:

Atender as demandas crescentes do transporte fluvial no principal corredor hidroviário brasileiro, no caso a hidrovia Amazonas-Solimões, servindo de alternativa para cargas que têm como origem ou destino diferentes pontos da região da Amazônia Ocidental.

Já conhecido pela Festa do Abacaxi, o distrito tem auxiliado na geração de recursos para a região que, aos poucos, vai se ajustando para receber um número cada vez maior de visitantes todos os anos. $E$ a presença de áreas naturais bem preservadas - em contraste com a abertura de outras para 0 plantio do abacaxi e a pecuária - vem gerando discussões para uma possível viabilidade para outras atividades turísticas relativas à agropecuária e meio ambiente.

O ponto de partida pode estar em um estudo que mostre as verdadeiras potencialidades da região para o agroturismo. O Ministério do Turismo (2003, p.36), monitorando esse fenômeno no interior brasileiro, orienta que:

\footnotetext{
Para a estruturação do segmento, é preciso que sejam inventariados os recursos naturais, artificiais materiais e imateriais, aqui denominados de recursos turísticos, capazes de despertar o interesse do turista e motivá-lo a deslocar-se até a região. Deve-se estar atento às especificidades que marcam o "local" e que o tornam singular, identificando o que o diferencia de possíveis concorrentes e como os recursos turísticos podem ser lapidados e transformados em atrativos, constituindo-se em produtos e roteiros.
}

O órgão, por meio de um conjunto de orientações e diretrizes, aconselha que se faça uso da experiência dos moradores, que conhecem o lugar; que se estimule a criação de estabelecimentos próximos dos núcleos emissores; a inserção de atrativos naturais que estão fora das propriedades rurais dentro de roteiros de visitação. Muitas áreas em Novo Remanso se dedicam ao cultivo do abacaxi e outros gêneros em larga escala que abastecem os mercados da Região Metropolitana de Manaus e em municípios próximos (Figura 3). 


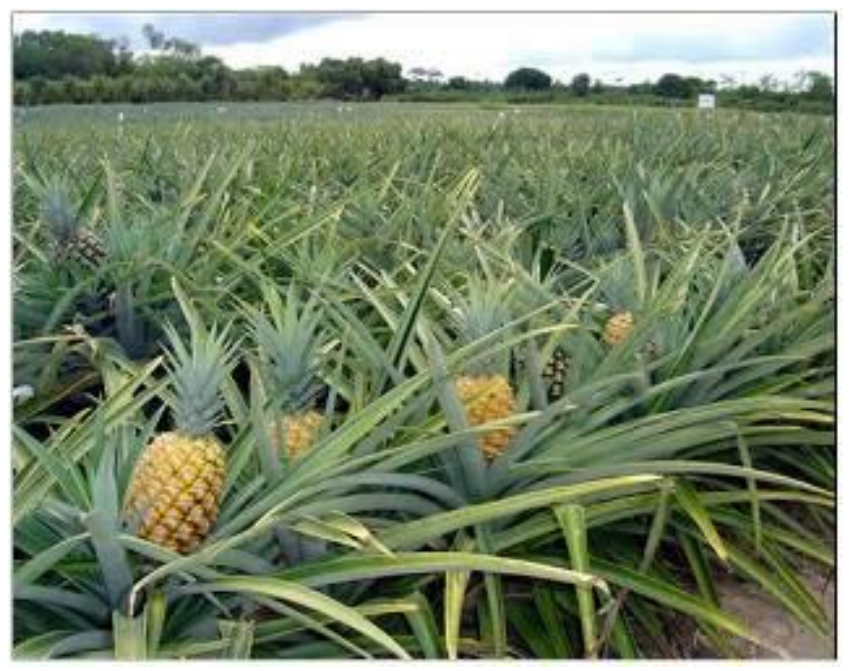

Figura 3: Plantação de abacaxi em Novo Remanso. Fonte: amazonianarede.com Figure 3: Pineapple's plantation in Novo Remanso. Source: amazonianarede.com

A abertura dessas fazendas a visitantes e a criação atividades de entretenimento e roteiros de visitas propiciaria um aumento na renda não apenas dos próprios donos, mas também dos trabalhadores sem precisar comprometer a produção e os trabalhos internamente realizados, pois o turismo rural, na sua essência, se dispõe a proporcionar uma experiência com a ruralidade local, sem comprometer suas funções, mas tão somente focá-las como atrativos. Outros serviços poderiam ser agregados para acentuar os bons predicados do meio rural, como cantinas e restaurantes com comidas típicas, serviços de passeios a cavalos ou jipes no interior dos estabelecimentos rurais, casas de artesanato e outros atrativos.

No caso dos trabalhadores da agricultura familiar, para onde uma parcela significativa da produção atende ao mercado local de Novo Remanso, atividades voltadas para a chegada de possíveis visitantes também seria uma opção geração de renda à unidade familiar, caso uma estrutura fosse implantada para recepcioná-los. Um bom programa de capacitação e capital investido, e mesmo uma estrutura simples e poucos recursos não deixariam muito a desejar se comparadas a uma fazenda pelo fato de abordar o lado mais simples do campo, o que também atrai certo público em condição financeira mais abastada. É importante frisar que de pouco ou nada adiantará a melhor cadeia de estruturação sem saber quais os interesses do turista; é necessário saber quem é ele, de onde vem e quais suas perspectivas quanto ao que procura. E o Ministério do Turismo (Idem) traçou o perfil do turista interessado nesse segmento:

São moradores de grandes centros urbanos; possuem entre 25 e 50 anos; são casais com filhos. Têm formação superior e a maioria pós-graduação; são de classe média para média alta. Usam automóvel próprio ou vans; deslocam-se, geralmente, em um raio de até $150 \mathrm{~km}$ do núcleo emissor; fazem viagens de curta duração - fins de semana e feriados; são apreciadores da gastronomia típica regional; possuem 
elevado nível de onisciência a respeito das questões ambientais; valorizam produtos autênticos e artesanais.

Admite-se que tal perfil pode variar em determinadas regiões, é de posse dessas informações que o homem do campo deve se ajustar se deseja o sucesso de seu empreendimento. Outra condicionante de bom desempenho é a divulgação da iniciativa em outros lugares. Em localidades pequenas uma boa alternativa é a organização de feiras agroculturais em locais amplos, de fácil mobilidade para atrair as populações locais e visitantes, com exposição de itens primários com alto valor agregado e serviços como artesanato, gastronomia, fotografias e elaboração de excursões pela região; uma oportunidade para que tanto pequenos empreendedores e sitiantes quanto grandes fazendeiros exponham os potenciais de seus respectivos estabelecimentos rurais. Explorar também a riqueza natural ali presente pode, sem dúvida, gerar um bom aproveitamento econômico, pelo fato de que o turismo rural valoriza o que seria a transição do espaço urbano alterado e consolidado com o natural e conservado. Buarque (2004) ressalta a relevância de impulsionar o potencial local e o aumento das oportunidades, condicionando isso a conservação dos recursos naturais, como condição para a qualidade de vida dos habitantes. Desenvolver, de modo sustentável, as áreas rurais abordam alternativas que visam fazer sobressair mais o lado agrário a partir de mecanismos simples, que não necessitam de muita complexidade, mas de uma intervenção com mínimos impactos sobre o meio ambiente, como esclarece Zimmermann (1996, p. 40):

A abertura da instalação familiar para o público (turista), de modo geral, necessita de complementações, no entanto não deve sofrer mudanças que sejam notadas pelo usuário como, por exemplo, a construção de novos prédios mais modernos. A harmonia do meio deve permanecer na observação do todo e isto vale desde a preservação ambiental, passando pela manutenção da arquitetura típica e chegando à atividade produtiva.

Conciliar turismo rural com ecológico pode ser uma realidade ainda que ambos sejam distintos em seus significantes essenciais, funções e, até mesmo, quanto ao seu próprio público alvo.

\section{Turismo rural: um segmento crescente}

O Ministério do Turismo (2003, p.11), no papel de definir esse modelo turístico dito genuinamente brasileiro, definiu o turismo rural como:

O conjunto de atividades turísticas desenvolvidas no meio rural, comprometidas com a produção agropecuária, agregando valor a produtos e serviços, resgatando e promovendo o patrimônio cultural e natural da comunidade. 
Trata-se de um segmento crescente em todo Brasil, que visa "valorizar a ruralidade" com maior comprometimento com as atividades agropecuárias, agregando valor a produtos e serviços, além do resgate e promoção dos patrimônios locais, sejam eles naturais, culturais, ou mesmo ambos. A Região Amazônica e outros biomas assumem condição peculiar dentro deste departamento porque o turismo rural também se identifica com outros tipos, como o ecológico e o etno-turismo. Sansolo (2003, 2003, p.7), ao abordar a atividade turística convencional na Amazônia, e sua noção de território, coloca que o turismo:

(...) Tem sido também, uma das alternativas escolhidas pelo vetor tecno-ecológico como meio de viabilizar o atendimento às demandas geradas pelas diferentes instâncias políticas desde a local, passando pela regional, nacional e internacional. Contudo, pode-se distinguir modelos diversos de implementação de empreendimentos turísticos que tem na natureza sua base de valor.

O autor ainda destaca a relevância do turismo na Região Metropolitana de Manaus - onde também se encontra Novo Remanso -, como alternativa econômica para diminuir sua dependência extrema do pólo industrial e cuja mobilização tem envolvido aparelhos públicos, como prefeitura e as universidades, além da iniciativa privada nacional e internacional, também almejando captar oportunidades de investimento para explorar economicamente este setor. Indicadores do turismo local, divulgados pela AMAZONASTUR, mostram que, em 2011, mais de 755 mil turistas passaram pelo Estado, sendo 266 mil destes estrangeiros, representando um crescimento de mais de $12 \%$ em relação a 2010. Somando o período 2003 2011, no qual a pesquisa está baseada, e incluindo os principais segmentos hotelaria urbana, pesque e pague, hoteis de selva e cruzeiros marítimos - o Amazonas recebeu 4.238.418 visitantes, entre brasileiros e estrangeiros. Os números volumosos apontam a preferência pelo ecoturismo, embora outras modalidades estejam crescendo consideravelmente. A ideia de desenvolver 0 turismo em áreas rurais é inusitada em um estado como o Amazonas, que possui atrativos próprios, porém projetos-piloto, como o município de Rio Preto da Eva, a $78 \mathrm{~km}$ da capital, mostram a força do segmento. Em todo Brasil, a expansão do agroturismo deve-se à visão do mundo rural sobre as oportunidades de diversificação das atividades econômicas sem comprometer o setor primário. Padilha (2010, p.41) comenta que o desenvolvimento e expansão do turismo rural:

Justificam-se pelo número de propriedades rurais que estão incorporando atividades turísticas em seu portfólio. Por isso, importante se faz o estabelecimento de ações para estruturação e caracterização desse tipo de turismo, a fim de que essa tendência não ocorra desordenadamente. Só assim se poderá consolidar o turismo rural como uma opção de lazer para o turista e uma importante e viável oportunidade de geração de renda adicional para os produtores rurais. 


\section{PNTRAF: Uma alternativa economicamente viável}

A Lei $n^{0} 11.326$ (2006) ajudou a estabelecer as diretrizes para o estabelecimento da agricultura familiar no Brasil e, entre elas, traça o perfil do homem do campo, como:

(...) aquele que pratica atividades no meio rural, atendendo, simultaneamente, aos seguintes requisitos: I - não detenha, a qualquer título, área maior do que 4 (quatro) módulos fiscais; II - utilize predominantemente mão-de-obra da própria família nas atividades econômicas do seu estabelecimento ou empreendimento; III - tenha percentual mínimo da renda familiar originada de atividades econômicas do seu estabelecimento ou empreendimento, na forma definida pelo Poder Executivo; IV - dirija seu estabelecimento ou empreendimento com sua família.

A mesma lei ainda beneficia outras categorias, como silvicultores, pescadores e também comunidades indígenas, onde todas estas devem atender aos requisitos exigidos no Art. $3^{\circ}$ da Lei. Outro progresso dentro da categoria que ajuda no fortalecimento do turismo rural no Brasil foi a criação do Programa Nacional de Turismo Rural na Agricultura Familiar (PNTRAF) que, segundo o Ministério do Turismo (2003, p. 21), é a atividade turística que:

(...) ocorre no âmbito da unidade de produção dos agricultores familiares que mantêm as atividades econômicas típicas da agricultura familiar, dispostos a valorizar, respeitar e compartilhar seu modo de vida, o patrimônio cultural e natural, ofertando produtos e serviços de qualidade e proporcionando bem-estar aos envolvidos.

Dentro do contexto amazônico, segundo o PNTRAF/AM (2012, p.3), o programa em si conta com objetivos que, embora generalizados no aspecto nacional, respeitam integralmente as particularidades e potencialidades de cada região em que é implantado. Os objetivos do programa no estado são:

I - Promover oficina de multiplicadores e elaboração de projetos técnicos; implantar o turismo rural em vários municípios do Amazonas; II - incentivo à organização social local para o gerenciamento compartilhado do desenvolvimento do programa; III - parcerias com as prefeituras municipais, com inventários das ofertas do Turismo Rural na Agricultura Familiar; IV - promover, planejar, desenvolver, assessorar, acompanhar e monitorar as ações em cada município.

Outro lado interessante dela aborda a cultura do lugar, cujo aproveitamento econômico ainda pode contribuir para expressar e enraizar o modo de vida, costumes e tradições ali presentes, oferecendo um substantivo 
próprio, um "sobrenome" àquele espaço. Zimmermann (1996) comenta que o turismo rural ainda é uma oportunidade de oferecer ao visitante o convívio com costumes e hábitos diferentes da sua vivência urbana, preservando e reavivando costumes locais.

\title{
Outros aspectos
}

Por mais promissor que possa ser o turismo rural em uma localidade com forte potencial, como Novo Remanso, é fundamental salientar que seria necessária boa vontade do poder público - na forma, por exemplo, de obras públicas dentro do distrito e parcerias para abertura de crédito ou empréstimos - mas também dos próprios interessados no setor, como fazendeiros, sitiantes e outros grupos sociais, para que futuras iniciativas voltadas para esse segmento obtenham sucesso. De fato, trata-se de uma boa alternativa de geração de renda que não compromete as funções do campo, mas viabiliza a sua importância, e cujo grupo mais beneficiado seriam os agricultores familiares. O pequeno proprietário, cuja área também é casa, trabalho e fonte de sobrevivência, tem sido apoiado nos últimos anos através de incentivos e programas como o TRAF e o Programa Nacional de Agricultura Familiar (PRONAF), do Ministério do Desenvolvimento Agrário (MDA). Contudo, Ruschmann (2001, p.72) esclarece que o turismo rural:

\begin{abstract}
Não representa solução para os problemas do campo. Tratase, entretanto, de uma opção empresarial, que pode trazer efeitos econômicos positivos, conseguindo contrabalançar, uma eventual desintegração das atividades tradicionais. Porém, para tornar-se um fator de desenvolvimento, deverá ser contemplado em um plano econômico estratégico, em nível local e/ou regional. Esse plano deverá considerar os aspectos relacionados com 0 desenvolvimento social, ambiental, físico e administrativo, estimulando a diversificação da base econômica, por meio de atividades complementares.
\end{abstract}

Curiosamente um dos motivos da proposta de emancipação de Novo Remanso é o fato de que os próprios moradores do distrito alegam a falta de investimentos públicos por parte da prefeitura de Itacoatiara, e defendem a boa capacidade de produção agrícola como capaz de prover recursos para o possível novo município. O turismo ecológico pode ser uma grande aposta nas regiões do Paraná da Eva (Figura 4) e rio Urubu, envolvendo Novo Remanso e os distritos de Engenho e Lindoia, devido à existência de unidades de conservação, cachoeiras (como a famosa Cachoeira de Lindoia) e áreas propícias para a prática de esportes de aventura (trekking, caiaque, etc.).

A localidade ainda comanda pequenas manifestações culturais na região, como as Festas do Abacaxi e do Peão de Boiadeiro, que atrai grande número de pessoas da Região Metropolitana de Manaus. Entretanto, também foram encontrados aspectos negativos: em visita recente foi observado que a infraestrutura básica do local está comprometida, precisando de melhorias na 
pavimentação e calçamento das ruas, iluminação pública, reparos na entrada fluvial. Novo Remanso também tem mostrado números negativos, apresentando um dos maiores índices de violência rural no Estado, aumento no número de roubos e assaltos, tráfico de drogas e prostituição. Um problema recente, decorrente da possível emancipação, é a especulação imobiliária, com a compra de casas e terrenos em áreas afastadas do núcleo principal, desmatamento de áreas verdes e queimadas. A presença de terras indígenas na região do rio Urubu, assentamentos do INCRA podem dificultar esse projeto de separação, tornando a situação ainda mais tensa, pois há opositores ao novo município que alegam que se há interesses de políticos e particulares no processo.

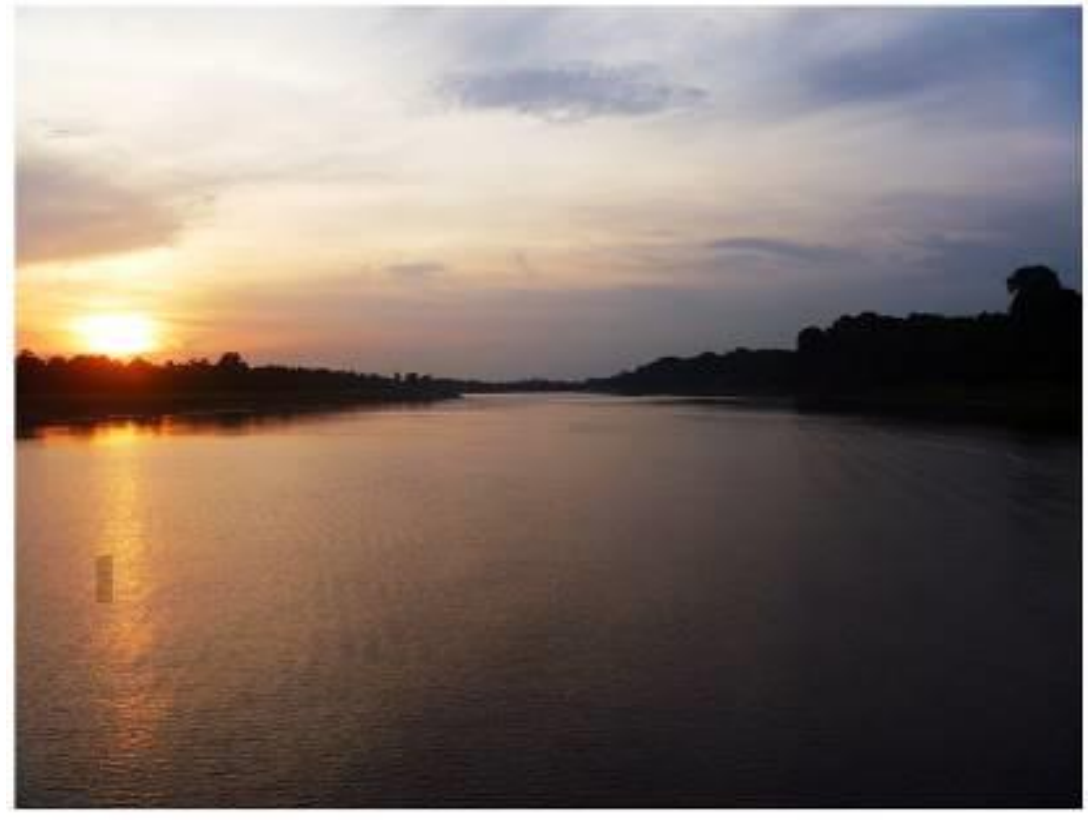

Figura 4: Paraná da Eva, próximo a Novo Remanso, zona rural de Itacoatiara.

Fonte: PACHECO, M. V.

Figure 4: Paraná da Eva's region, near Novo Remanso, rural zone from Itacoatiara.

Source: PACHECO, M.V.

A construção do Terminal Portuário de Novo Remanso (TPNR) mostra através do seu RIMA (2015) os impactos positivos, positivando a geração de empregos, com temporalidade permanente, aumento da massa salarial da população empregada e aumento das receitas fiscais decorrentes da operação do empreendimento. A qualificação de pessoal na região também é uma realidade positiva que foi notada, com a oferta de cursos profissionalizantes e cursos técnicos em várias áreas por instituições públicas, não ligadas ao empreendimento. Do ponto de vista ambiental o documento descreve impactos ambientais mitigáveis e passíveis de constante monitoramento, como perda da cobertura vegetal, contaminação das águas superficiais nas proximidades do terminal, considerando, portanto, "um empreendimento viável do ponto de vista ambiental, desde que atendidas às recomendações apresentadas neste EIA/RIMA.". 


\section{Considerações finais}

O mapa que aponta a localização de Novo Remanso (pág. 02) mostra a região como privilegiada do ponto de vista geoeconômico, que pode ser explorada ainda nos aspectos logístico e ambiental. No primeiro aspecto, uma saída terrestre e outra via fluvial torna-se vantajosa para escoar a produção agropecuária para Manaus, Baixo Amazonas e região do Madeira. Mas a Vila ainda apresenta muitas dificuldades que precisam ser sanadas para poder debater o "divorcio" com Itacoatiara, e mesmo o processo de separação não garante o sustento com as próprias pernas. Os turismos rural, ecológico e cultural aparentam ser uma alternativa econômica viável e fortemente relacionada com o setor primário, mas ainda obriga o distrito a rever sua escassa infraestrutura básica e turística, melhorias sociais, imprescindíveis para o pleno desenvolvimento destes segmentos.

\section{Referências}

BRASIL. Ministério do Turismo. Diretrizes para o Desenvolvimento do Turismo rural no Brasil. Brasília: 2003.

BRASIL. Lei no 11.326 de 24 de Julho de 2006. Estabelece os conceitos, princípios e instrumentos destinados à formulação das políticas públicas direcionadas à Agricultura Familiar e Empreendimentos Familiares Rurais. Diário Oficial da União. Disponível em: www.planalto.gov.br/CCIVIL/ Ato20042006/2006/Lei/L11326. Acesso em: 19 de Novembro de 2011;

BUARQUE, S.C. Construindo o desenvolvimento local sustentável. Rio de Janeiro: Gramond, 2004;

ESTATÍSTICAS DO MEIO RURAL. Departamento Intersindical de Estatística e Estudos Socioeconômicos; Núcleo de Estudos Agrários e Desenvolvimento Rural. 2 ed. Brasília: MDA: DIEESE, 2006;

Novo Remanso reivindica emancipação. Disponível em: $<$ http://www.vermelho.org.br/am/noticia.php?id secao=52\&id noticia=13687> Acesso em 17 de Novembro de 2011;

PADILHA, A.C.M. Estratégia \& Conhecimento: demandas emergentes no turismo rural. São Luís do Maranhão: EDUFMA, 2010;

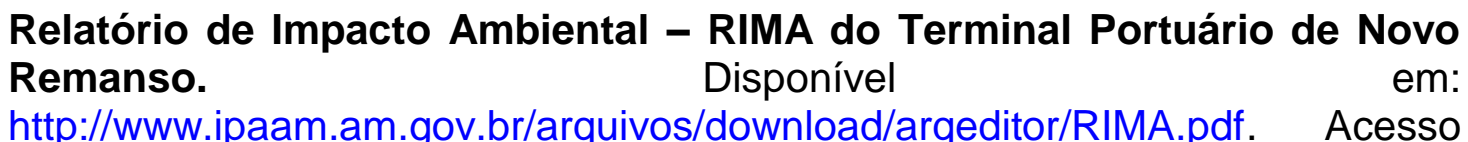
em: 22 de Setembro de 2015;

RUSCHMANN. D.V.M. O turismo rural e o desenvolvimento sustentável. In: ALMEIDA, J.A., FROHLICH, J.M.; RIEDL, M. (orgs.) Turismo Rural e desenvolvimento sustentável. São Paulo: Papirus, 2000. Coleção Turismo. (p.72);

SANSOLO, D.G. Turismo e Sustentabilidade na Amazônia: um novo conteúdo territorial e a experiência em Silves. Pasos (El Sauzal), Tenerife-Espanha, v. 1, n.1, p. 39-50, 2003; 
Suframa aposta em turismo rural no Amazonas. Disponível em: $<$ http://agenciabrasil.ebc.com.br/noticia/2008-04-06/suframa-aposta-emturismo-rural-no-amazonas > Acesso: 30 de Setembro de 2012, às 14h44;

Turismo Rural na Agricultura Familiar no Amazonas. Disponível em: $<$ http://www.seplan.am.gov.br/arquivos/download/argeditor/turismo rural.pdf>. Acesso: 02 de outubro de 2012, às 14h38;

ZIMMERMANN, A. Turismo Rural: um modelo brasileiro. Florianópolis: Ed. Do Autor, 1996.

Marcelo Veras Pacheco: Centro de Educação Tecnológica do Amazonas, Manaus, AM, Brasil.

E-mail: marcelopacheco77@hotmail.com

Link para o currículo Lattes: http://lattes.cnpq.br/1649275307678638

Data de submissão: 30 de agosto de 2016

Data de recebimento de correções: 11 de dezembro de 2017

Data do aceite: 11 de dezembro de 2017

Avaliado anonimamente 